\title{
O acolhimento dos refugiados no contexto português: Educação como dimensão
}

\section{da integração.}

\section{Refugee reception in Portugal: Education as a dimension of integration}

\author{
Glasielle Souza, Pedro D. Ferreira \\ Universidade do Porto
}

\begin{abstract}
Resumo
Este trabalho pretende explorar a educação como dimensão da integração no acolhimento dos refugiados no contexto português. Realizaram-se entrevistas a pessoas-chave das organizações que coordenam o processo e questionários por email às instituições de todo o país inscritas na plataforma a partir da qual tem sido feita a colocação dos refugiados. Os resultados mostram que, na dimensão educativa, é relevante a aprendizagem da língua, tanto pelo estabelecimento de programas específicos, como pelo reconhecimento das dificuldades sentidas no acesso aos mesmos, afirmando-se que a inclusão em contextos de aprendizagem da língua tem implicações na integração potenciando a procura de trabalho.

Palavras chaves: Acolhimento, refugiados, integração, educação.
\end{abstract}

\begin{abstract}
This research has the purpose of explore education as a dimension of integration in the reception of refugees in the Portuguese context. For this purpose, interviews were conducted, with crucial persons of the institutions. This persons coordinate the process. Questionnaires by e-mail to organizations registered on the platform from which the placement of the refugees has been made, from all over the country, were also conducted. The results show us that, in the education dimension, relevance is given to language learning, either by the establishment of specific programs as by recognition of accessing difficulties, we can affirming that inclusion in language learning contexts have direct implications for integration, empowering the active labor demand.
\end{abstract}

Keywords: Reception, Refugees, Integration, Education.

\section{Educação e integração}

A Educação é uma ferramenta fundamental na integração social de pessoas migrantes e refugiadas. Esta engloba a aprendizagem e treinamento da língua, reciclagem de habilidades, aprendizagem da cultura local e atuação dos serviços locais, ou seja, todo o processo normativo que é regido numa determinada sociedade. Estes são instrumentos que podem ser aprendidos através de intervenções educativas e são capazes de transpor barreiras estruturais em qualquer ambiente de acolhimento.

A educação nesse processo deve enquadrar possibilidades e oferecer locais e condições de compreensão e acolhimento. Lugares onde se ouve a voz e onde se passa a conhecer os nomes. Ainda que por vezes sejam espaços provisórios e móveis. Não podemos esquecer que muitas vezes as pessoas acolhidas já tiveram algum tipo de formação necessitando sobretudo de se familiarizarem com os códigos que existe na sociedade que os acolhem. A educação, dentro deste cenário deve ser pensada tendo em conta situações rotineiras de necessidades básicas e da compreensão dos códigos do modo de vida nesta nova sociedade. Tratando-se de adultos, devemos partir de um diálogo que consiga atravessar culturas, regras e que promova encontros. Não se pode ignorar que as pessoas têm escolaridades diferenciadas e a formação para a aprendizagem da língua tem de ter esse cuidado. O desafio que se coloca é, portanto o de construir uma "educação que aprende no caminho, que aprende com os peregrinos, que aprende na peregrinação, [que]se aproxima dessa educação transitória em movimento, em ação" de forma a proporcionar que seja "uma educação que aprende com o deslocamento humano. Com as pontes que representam esses deslocamentos." (Silveira, 2008, p. 98). Não se pode anular o que essas pessoas trazem com elas, não se pode negligenciar suas experiências e diferenças, é preciso trazê-las para o processo educativo para que este se traduza em algo capaz de apoiar um processo de integração em que se constrói o novo sem anular o que existe. O hibridismo é uma aposta de mão dupla, onde as fronteiras culturais são perpassadas nos dois sentidos, numa interpretação cultural mútua, numa integração que não recusa o ato de acolher. Nesse sentindo, ao tratar a dimensão da pluralidade cultural "trata-se fundamentalmente da discriminação, diferença, desigualdade e exclusão" (Silveira, 2008, pp. 99-100) temas que não podem ser ignorados na prática educativa.

\section{A Educação como dimensão de integração}

Pensar o acolhimento e a integração é pensar sobre a nossa relação com a diferença, pois os recém-chegados a uma sociedade são "considerados como o caso clássico do Outro, aquele que não pertence" (Pennix e Martiiello, 2010, p.129). Isto coloca o trabalho do acolhimento e integração perante a necessidade de reconhecer que a relação com o diferente deve ter como ponto de partida a 
compreensão de que o "outro é diferente e nós também somos! A diferença está na relação entre diferentes" (Stoer \& Magalhães, 2005, p.143). Uma forma de compreender a integração que salienta esta dimensão biunívoca está presente na proposta apresentada pelo ECRE (2002). Esta instituição propõe que se olhe a integração como um processo de mudança dinâmico e two-way (ou recíproco), de longa duração e multidimensional. Isto pressupõe esforços e mudanças tanto nas pessoas acolhidas como nas sociedades de acolhimento. Os refugiados devem estar preparados para se adaptarem aos modos de vida da sociedade de acolhimento ao mesmo tempo, a sociedade de acolhimento deve mostrar-se disponível para a aceitação das pessoas acolhidas como parte da comunidade. Isto não pode exigir a perda de uma identidade cultural própria quer de uns quer de outros e deve explicitamente preocupar-se com a adaptação das instituições públicas facilitando aos recém-chegados o acesso aos recursos de que estes necessitam (ECRE, 2002). O processo de integração requer posturas que percebam que a "eficácia da integração é influenciada pelas experiências [desde o] momento da chegada a um novo país" (Ager \& Strang, 2010, p.596) e que passem por "providenciar condições mínimas de bem-estar, para minorar o sofrimento, como o direito ao trabalho, o direito a reconstituir as suas redes familiares, o direito a decidirem eles próprios as suas trajectórias de vida." (Santinho, 2012b:13). Entre as dimensões centrais para se conseguir uma integração bem-sucedida Ager e Strang (2008) identificam quatro: o acesso a habitação, saúde, emprego e educação. É sobre a dimensão da educação que se debruça a pesquisa aqui apresentada.

\section{O processo metodológico}

Para compreender o modo como tem sido pensado e implementado o acolhimento a refugiados em Portugal, realizaram-se sete entrevistas, a representantes do Conselho Português para os Refugiados - CPR (1), Alto Comissariado para as Migrações - ACM (1) e Plataforma de Apoio aos Refugiados - PAR (1), a eurodeputados (2) de forças políticas distintas e a técnicos (2) das instituições de acolhimento. Para obter mais informações quanto à forma como tem decorrido o acolhimento foi elaborado um questionário enviado por email às instituições de acolhimento, de todo o país, parceiras da PAR (num universo de 50 instituições, obtiveram-se 30 respostas). Os resultados que aqui serão apresentados refletem apenas a parcela dos resultados globais com maior relevância para explorar a dimensão educativa.

\section{A educação no acolhimento dos refugiados no contexto português "resultados de uma pesquisa"}

No contexto português, o que se pode verificar é que a educação, na sua dimensão mais formal, tem uma importância crucial na integração das pessoas no novo contexto social. No caso dos adultos esta se encontra diretamente relacionada com oportunidades no mercado de trabalho, uma vez que, no mercado formal de trabalho são frequentemente exigidos o domínio do idioma local e que seja comprovado um determinado nível académico/ de escolaridade. Compreende-se facilmente que ambas são barreiras difíceis de transpor para muitos refugiados e as instituições de acolhimento deram conta disso mesmo.

As crianças e jovens conseguem mais facilmente se integrar no processo de educação formal desenvolvido na sociedade de acolhimento. $\mathrm{O}$ direito a frequentarem as escolas públicas é-lhes conferido pela legislação portuguesa (artigo $74^{\circ}$ da constituição, alínea i e j) e o processo encontra muito menos barreiras do que no caso dos adultos.

Uma das formas como a educação tem sido usada como instrumento potenciador da integração tem sido através da criação de oferta formal de programas ou da criação de iniciativas aos diferentes níveis de ensino que possam acolher e dar resposta a imigrantes e refugiados. Quer isto dizer que tem havido iniciativas ao nível da: 1) Educação básica e secundária dirigida a crianças e jovens; 2) Ensino superior dirigido a estudantes refugados forçados a interromper os seus percursos académicos; 3) Ensino da língua portuguesa a adultos (certificado pelo IEFP). Assim:

1). Em relação a educação no ensino básico e no ensino secundário, a integração de crianças refugiadas nas escolas tem-se baseado no Guia de Acolhimento (Educação Pré-Escolar, Ensino Básico, Ensino Secundário) proporcionado pela Agenda Europeia para as Migrações. Embora existam outros programas dirigidos à integração dos migrantes e refugiados na escola, olhámos mais de perto para as questões da aprendizagem básica da língua. É de salientar que quando a criança é recém-chegada e não domina a língua portuguesa, ela é posicionada no nível A1 de proficiência linguística da disciplina Português Língua Não Materna (PLNM). Desta forma, os estudantes que sejam posicionados nos níveis de proficiência linguística de Iniciação "seguem o currículo de PLNM e não o currículo da disciplina de Português do ano de escolaridade em que se encontram." (AEM, 2016, p.11). Se já existir algum domínio prévio da língua, “deverão ser aplicados testes de diagnóstico para posicionamento em nível de proficiência linguística.” (AEM, 2016, p.11).

2). No ensino superior, tem-se destacado o trabalho de integração realizado ao abrigo da Plataforma Global de Assistência a Estudantes Sírios, promovida pelo exPresidente Jorge Sampaio. No dia 27 de setembro de 2015, chegaram a Portugal 40 estudantes Sírios que haviam interrompido seus estudos devido à guerra civil na Síria. Além desse projeto, houve também outros parceiros com outras iniciativas com a mesma finalidade 3). As maiores dificuldades, no que toca à educação formal, têm surgido nas aulas de língua portuguesa para adultos. $\mathrm{O}$ "ensino do Português é o que tem falhado. O Instituto de Emprego e Formação Profissional não tem tido capacidade para organizar turmas orientadas para pessoas tão diversas." (Santinho in O Público, 2016). Esta aprendizagem da língua se encontra dentro do projeto que existe há 16 anos destinado aos imigrantes, com a designação de "Português para todos", mas no caso da integração dos refugiados têm ficado patentes dificuldades acrescidas. Dada a centralidade da língua para diferentes tarefas quotidianas com elevado impacto 
na integração, as instituições de acolhimento têm por vezes iniciativas não-formais que promovem como respostas emergentes de ensino da língua (explicitaremos mais adiante).

\section{Dificuldades sentidas pelas instituições de acolhimento e pelos seus técnicos:}

A partir do inquérito às instituições de acolhimento foi possível identificar duas áreas principais em que se expressam tanto as dificuldades sentidas pelas instituições na sua relação com os refugiados como as dificuldades verbalizadas pelos refugiados na sua relação com estas: as questões da língua (e da comunicação) e as questões do acesso ao trabalho. É significativo que oito (em 27) instituições tenham salientado sentir que a barreira linguística é uma das suas principais dificuldades - "é da compreensão mútua. Nem eles conhecem o português nem nós conhecemos a língua árabe" (instituição A) - denotando também a inexistência ou insuficiência da disponibilidade de intérpretes que possam facilitar o contacto entre refugiados $\mathrm{e}$ instituições. Das dificuldades sentidas pelos refugiados aquelas que as instituições mais identificam são as que se prendem com o acesso ao trabalho (9 em 27 instituições referem-no) e as dificuldades com a língua do país de acolhimento (referida por 8 em 27 instituições). Por vezes estas aparecem articuladas já que em muitos casos a sua relação é estreita - "dificuldade na adaptação da língua e consequentemente integração no mercado de trabalho" (instituição A) - e afecta o bem-estar das pessoas acolhidas: "o maior desafio para esta família é conseguir viver em condições materiais mais modestas do que as que tinham na Síria" (instituição G). Há em algumas destas instituições a consciência de que a resolução articulada destas questões não é simples já que "se tivermos em consideração toda a conjuntura em que os refugiados se encontram: habilitações literárias e experiência profissional que é muitas vezes difícil de comprovar, problemas relacionais que se prendem com a sua cultura, em especial em relação ao género. Há todo um trabalho de integração que pressupõe muito trabalho e algum tempo para alcançar resultados consistentes." (instituição $\mathrm{H}$ ).

Sobre o que está sendo feito nas dimensões da educação, foi possível verificar que não há alterações ou critérios nos programas oficiais de aprendizagem da língua portuguesa para os novos estrangeiros, e ainda, perceber que o fator dispersão territorial dos refugiados, uma estratégia intencional no modelo português de acolhimento, aparece como um constrangimento uma vez que dificulta o processo de criação de turmas, já que o número de pessoas é insuficiente em alguns pontos do país. Uma reportagem no público relatou o assunto:

"a aprendizagem da língua portuguesa não obedece a um modelo pré-estabelecido, mas sim às ferramentas e meios que melhor oferecem condições para esta aprendizagem" fazendo-se o ensino "através de voluntários" por ser, nalgumas situações "a [forma] mais adequada a determinados contextos, em particular quando o modelo descentralizado de acolhimento não permite a constituição de turmas". (Ana Dias Cordeiro, público, 2016).

O mesmo foi relatado pelas técnicas entrevistadas. Havendo muitas vezes atrasos nas respostas formais de ensino da língua para adultos, as mesmas organizaram respostas a partir de recursos próprios.

"Tínhamos noção de que era extremamente importante ensinarmos a língua, portanto, também criamos muito rapidamente, logo - tipo, nem duas semanas depois eles já estavam a ter aulas diárias de português connosco, na própria instituição, sim. Nós fizemos uma rede de voluntários, e eles tinham aulas de português todos os dias connosco, eu sou também uma das professoras de português e foi, e acho que foi importante. Depois em dezembro, portanto eles chegaram a três de setembro, a cinco de dezembro eles tiveram também a oportunidade de ingressar num daqueles cursos de português para estrangeiros, que o instituto de emprego e formação profissional as vezes tem". (Técnica 1).

A experiência das instituições reforça a importância à aprendizagem da língua no processo de acolhimento. Note-se que é uma das dificuldades sentidas pelos refugiados e pelas instituições (dada a ausência em muitas delas de tradutores ou intérpretes) e que esse processo está diretamente relacionado com a questão do trabalho (ele também uma importante preocupação e dificuldade sentida pelos refugiados na visão das instituições). Neste sentido a integração dos adultos primeiramente passa pela aprendizagem da língua e a sua certificação, o que facilita o acesso ao mercado de trabalho.

As respostas ao nível das crianças são as que se encontram mais estruturadas:

[as] "crianças estão inscritas correspondente a idade que tem, o mais velho tem 10 anos numa escola primária, a seguinte tem agora 5, quando chegou tinha quatro, está na pré-primária, na mesma escola do irmão, portanto, e a bebê que tem 1 ano quase 2 está numa creche. Como qualquer outra criança portuguesa estaria, ou seja, os dois mais velhos têm ensino gratuito, tendencialmente gratuito e mais a bebê não, tem ensino pago, não é um valor...dado as condições sociais dos pais, não é um valor extremamente elevado, mas paga como as famílias portuguesas pagam, pronto. Ela teve que ir para creche quando os pais foram para o ensino de português" (Técnica 1)

Ao esmiuçar a dimensão educativa nos primeiros níveis escolares, foi possível observar numa das falas das técnicas a existência de diferentes graus de escolaridade entre as crianças refugiadas (recolocadas) com o qual as escolas portuguesas têm de trabalhar: "esta família está há 8 anos em fuga porque já eram refugiados na própria Síria, e, portanto, o menino que tem 10 anos não teve escolaridade formal." (Técnica 2).

A educação das crianças está diretamente ligada às escolhas de que 'tipo' de escola essas crianças frequentam, pois quando o acolhimento é feito por instituições religiosas entender como a relação entre as religiões se comungam permite ampliar a visão de integração. Nesse sentido, foi possível analisar que há um claro entendimento de que se conduz a uma boa relação das mesmas, vê-se que o respeito é partilhado: "quando 
há celebrações na escola ou disciplinas que tem o caráter de prática religiosa a criança não vai, não frequenta, quando é outro tipo de formação que naturalmente está informada por valores cristãos o menino está, participa e os pais dizem que até é benéfico para ele.” (Técnica 2).

A educação permite uma melhor integração e isso se encontrou presente no discurso de uma das técnicas:

"temos um menino em termos de escolaridade muito bem integrado e fala perfeitamente o português, o menino de dez anos, aliás fala com todos os tiques das crianças portuguesas de dez anos, com aquele palavreado, com frases com: - 'tipo', tipo isso, tipo aquilo, fala igual. Foi proporcionado também praticar atividades extracurriculares, pratica judo, já ganhou duas medalhas no judo, pronto, o menino mais velho está de facto muito bem." (Técnica 2)

\section{Conclusão}

A educação é vista como uma ferramenta facilitadora para a integração em toda a sociedade e não se deve negligenciar. Esta é central no processo do acolhimento e integração das pessoas em novos contextos em conjunto com a dimensão do acesso ao trabalho, que se tornaram as principais dificuldades sentidas pelas instituições de acolhimento e identificadas por estas como estando entre as mais sentidas pelos refugiados. As barreiras linguísticas dificultam não só o trabalho das instituições de acolhimento, mas também a integração dos refugiados tendo consequências noutras áreas das suas vidas como o acesso ao mercado de trabalho.

Com a realização da pesquisa foi possível perceber que no que diz respeito as crianças e aos jovens, as respostas a nível da educação se encontram melhor estruturadas. Ou seja, são dadas respostas oficiais, existe enquadramento e recursos que permitem mais rapidamente encontrar contextos educativos nos quais as crianças e jovens se possam integrar. Quanto aos adultos, o fato das instituições de acolhimento estarem espalhadas pelo país, tem tornado mais lento e difícil o processo de ensino da língua, por vias formais. Percebemos serem muitas vezes as próprias instituições darem essas respostas assim que recebem as pessoas refugiadas, mas ficando estas dependentes dos recursos disponíveis nas mesmas instituições. Cabe ao IEFP, através do programa "Português para Todos", destinado a imigrantes, suprir essa lacuna, porém, neste momento existe uma demora nessas respostas, o que dificulta até mesmo, a procura de trabalho por parte dos refugiados. Sendo as questões linguísticas e as de acesso ao mercado de trabalho aquelas que mais parecem contribuir para dificuldades e barreiras à integração dos refugiados, seria importante repensar de que modo o modelo de acolhimento pensado para Portugal poderia ser alterado para melhor dar resposta a estas necessidades e assim melhor contribuir para a integração das pessoas acolhidas.

\section{Referências}

Ager, A. e Strang, A. (2010). "Refugee Integration: Emerging Trends and Remaining Agendas", Journal of Refugee Studies, 23 (4), 589-607. http://jrs.oxfordjournals.org/content/23/4/589.full.pdf + html

Ager, A. e Strang, A. (2008). Understanding Integration: A Conceptual Framework, Journal of Refugee Studies, 21 (2), 166-19. http://heinonline.org/HOL/Page?handle=hein.journals /jrefst $21 \&$ collection=journals \&id=170\&startid=\&endi $\mathrm{d}=195$

Agenda Europeia para as Migrações (2016). Guia de Acolhimento: Educação Pré-Escolar, Ensino Básico, Ensino Secundário. Editor: Direção-Geral da Educação.

Agenda Europeia da migração. Disponível em; http://www.refugiados.acm.gov.pt/agenda-europeiada-migracao/

Cordeiro, Ana Dias, Portugal esta a deixar refugiados sem estatuto e sem direitos, Público, 29 de abril de $2017 . \quad$ Disponível em: https://www.publico.pt/2017/04/29 /sociedade/noticia/ portugal-esta-a-deixar-refugiados-sem-estatuto-e-semdireitos-1770399

Decreto-Lei capítulo III, Direitos e deveres culturais artigo $74^{\circ}$ da constituição portuguesa. Disponível em: http://www.parlamento.pt/Legislacao/Paginas/Constit uicaoRepublicaPortuguesa.aspx.

ECRE (2002). Position on the Integration of Refugees in Europe. Londres: ECRE. http://www.ecre.org/topics/ areas-of-work/integration/179.html

Magalhães, A. M \& Stoer, S. R. (2005). A Diferença Somos Nós. Porto: Edições Afrontamento.

Penninx, R. e Martiniello, M. (2010). Processos e Políticas (Locais) de Integração: estado do conhecimento e ilações, em M. M. Marques (Coord.), Estado-Nação e Migrações Internacionais, Colecção Estudos Políticos, Lisboa: Livros Horizonte

Santinho, M. C. (2012). A importância da competência cultural no atendimento de saúde a refugiados e requerentes de asilo. Fórum Sociológico Serie III, 7381. https://sociologico.revues.org/594

Santinho, Cristina, Integração de refugiados: Há falhas no ensino de Português, Público, Lisboa, 9 de Novembro de 2016. Disponível em: https://www.publico.pt/2016/11/09/sociedade/noticia/ ensino-do-portugues-nao-acompanha-ritmo-dechegada-dos-refugiados-1750397

Silveira Junior, M. R. (2008). A travessia que mancha o corpo: imagens da imigração e a educação transitória. Tese de Doutorado, Faculdade de Educação, Universidade de São Paulo, São Paulo. doi: 10.11606/T.48.2008.tde-02022009-101601 